\title{
PÉREZ PÉREZ, José Antonio (coord.), Historia y memoria del terrorismo en el País Vasco I (1968-1981). Confluencias, Almería, 2021. 711 pp.
}

La publicación en 2016 de Patria, la obra de Fernando Aramburu, cinco años después del breve comunicado de octubre de 2011 que puso fin a cincuenta años de «actividad armada» de la organización terrorista ETA supuso un punto de inflexión en la cuestión del relato del terrorismo. Aramburu, como ya lo había hecho en obras anteriores, puso de manifiesto con toda la crudeza los otros efectos del terrorismo: la desmovilización y el silencio impuesto (algo común, por otra parte, a todos aquellos que quieren imponer un proyecto totalitario); y contribuyó de una manera decisiva a modificar la percepción del terrorismo.

La desaparición de ETA supuso prácticamente el fin de la actividad terrorista en España, uno de los países occidentales más golpeados por lo que Rapaport denominó como «tercera ola» del terrorismo, aunque tampoco quedamos al margen de la «cuarta ola» protagonizada por el terrorismo de corte yihadista. A partir de ese momento la cuestión que se iba a dilucidar era la del relato de los tiempos pasados. Ya lo avisó, pocos días antes del comunicado de ETA, el diario Gara. El mencionado periódico publicaba el 2 de octubre de 2011 un «aviso a los que quieran un relato de vencedores y vencidos: el que convenza, vencerá». La duda que se me plantea ante tal afirmación era de qué había que convencer.

Es evidente que se me ocurren muchas respuestas a tal dislate, pero sí es cierto que el relato se ha fragmentado en varias posibilidades. La primera, de uso y consumo interno de la autodenominada «izquierda abertzale», tan justificativo e inconsistente que solo sirve para tratar de mantener, mediante el derecho al pataleo, que todo lo que hicieron sirvió para algo. Una segunda línea, desideologizada aparentemente, busca pasar página equiparando todas las violencias y relacionando, en un todo, la Guerra Civil, el franquismo y la democracia. Se construye un relato endeble, poco matizado y que busca diluir el pasado reciente en uno más lejano, usando para ello el recurso a la memoria. Lo malo de esta corriente es que deja de lado a la Historia. La tercera línea, en la cual se inscribe esta obra, pertenece plenamente al campo de la Historia, de una historia académica (denigrada por la primera línea y soslayada por la segunda), pero que es la única capaz de documentar, objetivar y analizar el proceso de violencia, a la vez que aportar los elementos de análisis y conocimiento que nos permitan valorar de manera adecuada lo ocurrido.

La obra que comentamos no es un hecho aislado, sino que es el resultado de una línea clara de investigación que se suma a la numerosa bibliografía que ha analizado el problema terrorista desde diversas perspectivas. Sería largo de citar la nómina de autores, pero hay mencionar algunas de las aportaciones recientes más relevantes. Debemos mencionar los estudios sobre las víctimas (Domínguez, 2010); sobre la violencia en las calles y la cuestión nuclear (López Romo y Fer- 
Reseñas de libros

nández Soldevilla, 2012); el acoso a la derecha vasca (Angulo, 2018); la Iglesia (Ontoso, 2019); el rechazo pacifista a la violencia terrorista (Moreno, 2019) o la cuestión de las drogas (García Varela, 2020), por citar algunos de las obras más recientes.

Pero el libro que comentamos va un paso más allá. Se trata de ofrecer una visión global del fenómeno del terrorismo de manera integral, es decir, todas las formas de terrorismo que se han experimentado en el País Vasco, no solo el de ETA, y las diversas formas que este adoptó (el inmiscuirse en cuestiones ecológicas, la extorsión a los empresarios o la uniformización social). Para lograr este objetivo se plantea una ambiciosa obra en tres volúmenes, siendo éste el primero, centrado en el período 1968-1981, y al que seguirán otros dos dedicados a los periodos 1982-1994 y 1995 a 2011. La división cronológica no es arbitraria y en el primer volumen se aborda desde el origen del terrorismo, con la creación de ETA, hasta 1981, un año que marca un punto de inflexión en la historia reciente de España con la dimisión de Adolfo Suárez, artífice en gran medida de la Transición, y el fallido golpe de estado de febrero como antesala de la victoria socialista en las elecciones de 1982, y que también coincide con los años más mortíferos del terrorismo de ETA en el País Vasco con un total de 211 asesinatos entre 1979 y 1981.

Pese a que son muchos los aspectos que creo que se deben destacar de esta obra, hay tres que a mi entender son claves. El primero es que se coloca a las víctimas en el centro del relato, rompiendo de esta manera la espiral de silencio impuesta por el terrorismo. Esto tiene un efecto que me parece destacable, como es desviar el foco de atención de la organización terrorista - objeto central historiográfico de muchas y meritorias obras y de otras de calidad más cuestionable- y que en cierta medida ha marcado el conocimiento del tema. El pasar el foco de los terroristas a sus víctimas tiene a mi entender el efecto deslegitimador de no situar al terrorista en el centro y de este modo impedir uno de sus objetivos, que es la relevancia y constituirse con el elemento central del debate. El centro de atención no deben ser los asesinos, sino sus víctimas y el contexto en el que éstas se desenvolvían y en el que quedan sus familiares tras el atentado.

El segundo aspecto que me parece reseñable es la propia estructura de la obra. Frente a narrar una serie de atentados en sucesión cronológica, se opta por un análisis temático de la violencia en el País Vasco por grupos (guardias civiles, policías, cargos franquistas o empresarios) y de manera temática (Lemóniz o la uniformización social) para cerrar con un estudio de la violencia de extrema derecha que también tuvo su presencia destacada. La tercera cuestión que quiero destacar es el enorme trabajo de documentación y búsqueda de información que se ha llevado a cabo. La ingente documentación recopilada, y que se depositará en el Centro Memorial de Víctimas del Terrorismo, va a conformar un corpus documental de gran importancia e imprescindible para cualquier persona que se interese por estos temas. 
Reseñas de libros

Estamos, por tanto, ante el primer volumen de una obra que está llamada a convertirse en la referencia obligada para el estudio de la violencia en el País Vasco. Una obra que, en palabras de su coordinador, es «rigurosa y neutral pero claramente consciente de donde se encuentra el valor moral positivo», algo que ésta logra ampliamente.

Pedro Barruso Barés 